\title{
Real-Time Alerting for Medical Science and Healthcare
}

\author{
Yusuf Durachman, Sulistyo Andarmoyo, Phong Thanh Nguyen, K. Shankar, Robbi Rahim
}

\begin{abstract}
Particular in medical communication is can say as an underappreciated skill. By using ever-growing number of new infrastructure, apps are devices our reality has turned out to be progressively interconnected, numerous connections among specialists and patients are still amazingly dated. A great deal of delicate data is passed along face to face, however most different collaborations are done by means of telephone. Without the need to revive or physically demand data the Real-time applications receive and send data instantaneously. It could be devices that screens vitals and immediately streams those readings to a database or different devices or for connecting the patient with doctors it could be a simple application of chat.
\end{abstract}

Keywords- medical communication, patients, Real-time applications

\section{INTRODUCTION}

During the ongoing decade, fast headways in social insurance administrations and minimal effort remote correspondence have incredibly helped with adapting to the issue of less therapeutic offices. The combination of portable correspondences with wearable sensors has encouraged the move of medicinal services administrations from clinic-centric to patient-centric and is named as "Telemedicine" in the review [1-2]. In the bigger point of view, telemedicine can be of two kinds:

(1) Forward and store type, that needed obtaining of parameters of medical like in hospitals transmission of patients data to concerned specialist, vital signs, videos and images.

(2) Type of live communication, with additional requirements of good data speed and high bandwidth the presence of the patient and doctor is required $[3,4]$.

\section{THE BENEFITS OF REAL-TIME APPS IN HEALTHCARE}

Without the need to manually request or refresh information the application of real time send and receive the data. These applications can be a device that instantly streams readings and monitors vitals to other devices or a data or it could be a general application which connects the patients to doctor [5].

Revised Version Manuscript Received on 16 September, 2019.

* Correspondence Author

Yusuf Durachman, UIN Syarif Hidayatullah Jakarta, Indonesia. E-mail: yusuf_durachman@uinjkt.ac.id

Sulistyo Andarmoyo, Universitas Muhammadiyah Ponorogo, Indonesia.

Phong Thanh Nguyen*, Department of Project Management, Ho Chi Minh City Open University, Vietnam. E-mail: phong.nt@ou.edu.vn

K. Shankar, Department of Computer Applications, Alagappa University, India. E-mail: shankarcrypto@gmail.com

Robbi Rahim, Sekolah Tinggi Ilmu Manajemen sukma, Medan, Indonesia.

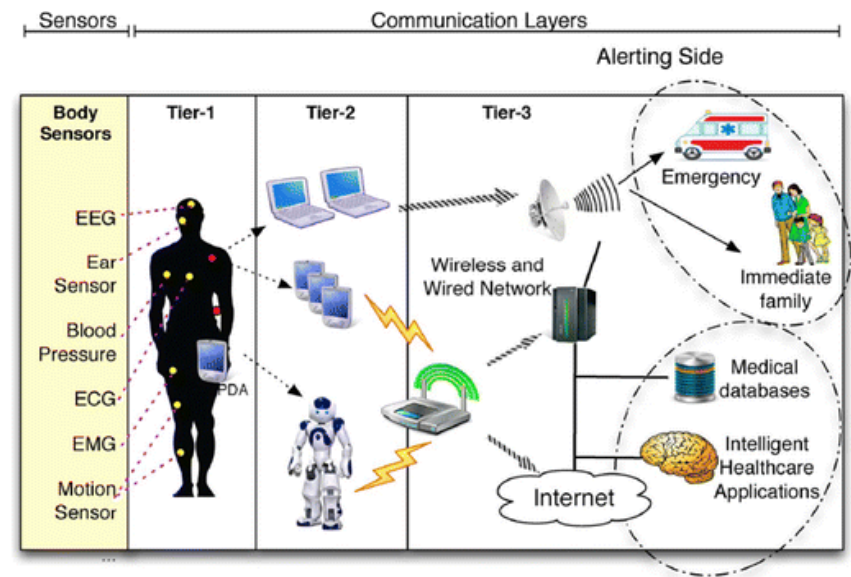

Figure 1: Real Time health monitoring system [6]

There are many real time applications that are properly used:

1. When patient need then access of doctors: With a doctor the instant communication enables patients to keep away from the need to call the workplace, plan an arrangement and go on off from work for a visit. The patients can easily communicate with a doctor or medical caretaker from the solace of their home utilizing projects like Presence when it need a quick bit of advice or a prescription updates.

The real-time communication power among specialists and patients is significant, however associations can possibly profit on the off chance that they're willing to embrace new arrangements. Luckily, incorporating real-time healthcare applications into existing correspondence frameworks isn't as entangled as it may appear.

2. Real-time monitoring in remote areas: From critical vitals like monitor readings remotely, heart rate and blood sugar levels applications can stream real-time data. The software can trigger an alert to a physician if these signals reach a particular value. For connected hospital devices both on the move and on-site this is a necessary feature.

3. Alerts and Smart notification: To any number of relevant users the real time applications can deliver necessary notification and alerts. For example when there is a new patient request then a program could alert a doctor. The real time applications can remind the patients and doctors for upcoming alter and ensure everyone on the same page [7] [8].

\section{FACTOR FOR SUCCESSFULLY DEVELOPED A REAL-TIME APPROACH}

It can possible to launch a successful new communications by using the three steps given below:

1. Take care of market and employee: what is the 
technology is used? who is going to use the application.

Listen to your employees and your market. What technology frustrates people who use it on a daily basis? To discover, hold workshops with an assortment of staff individuals to gather their info. It may facilitate a center gathering with a couple of patients to find out about their needs and wants.

2. Identify Potential use cases identification: Where do issues lie? Where are unnecessarily burning through cash? Where is information siloed, and how can it influence the association? Where is innovation so obsolete that it baffles workers? Recognizing these issues will make it simpler to pick constant arrangements that tackle the association's one of a kind issues.

3. Start with Smaller use cases and newer projects: Real-time capabilities making into an infrastructure or application from the beginning is a lot simpler than annihilating your current framework and supplanting it discount with an ongoing system. Start with experimental runs programs among a little gathering of workers to investigate issues before moving anything out to the whole group.

\section{E-HealthCARE AND Mobile}

In the previous decade, wearable devices and sensors have developed as key innovative articles which have significantly reformed the healthcare solutions of next generation. This is the period of ferocious challenge loaded up with monstrous pressure which prompts the discovery of different infections even in the individuals of early age. In addition, individuals are winding up more wellbeing cognizant in developing and developed nations. The scaling down of devices and sensors and propensity of individuals to be doctor autonomous have lead the analysts over the globe to think of various social insurance arrangements which are omnipresent as well as. Wearable medicinal gadgets (WMDs) fit for observing the absolute most regular physiological parameters-lead ECG, skin temperature, blood oxygen saturation, pulse, heart rhythm and so forth [9].

With the e-healthcare systems and mobile there are associated many challenges and aspects like:

- Efficient and secure management and data transmission
- Networks and data integration

-Implementation and architectural design issues

- Patient information and their data privacy maintaining

\section{VARIOUS E-HEALTHCARE MODELS AND SYSTEMS}

1. Smartphone and Cellular based e-healthcare systems A Mobicare cardio observing framework comprising of a phone installed with constant ECG handling calculations location of QRS complex, a bluetooth-enabled ECG sensor, user interface and a database of patient, a web-based server, Q onset, T offset- (MobiECG) [12].

2. E-healthcare systems based on Cloud With the evolvement of e-healthcare and mobile services advancements, the idea of health-cloud has developed. In [10], health monitoring of patient utilizing Health-Cloud has been displayed. At the point when the area of a portable patient changes, the related default passage likewise changes and, subsequently, the ideal mapping between the mobile and the server hub additionally changes.

3. E-healthcare modules of System on Chip (SoC) A compact framework on chip for ECG observing has been created [11] with low-control utilization which is fit for executing configurable usefulness. In a wireless ECG monitoring system with Bluetooth convention the $\mathrm{SoC}$ is executed in $0.18 \mu \mathrm{m}$ CMOS process and consumes $32 \mu \mathrm{W}$ from a $1.2 \mathrm{~V}$ while heart beat location application is running, and coordinated.

\section{Automatic Wireless Health Monitoring SYSTEM}

In hospitals now in recent days the health care sensors are playing a necessary role. Because of innovative technology the patient monitoring system is one of the major implementation. By using embedded technology to estimate the heartbeat and body temperature an automatic wireless health monitoring system is used utilized. Both temperature sensor and heartbeat sensor used in system. To monitor the patient condition these systems are used [13].

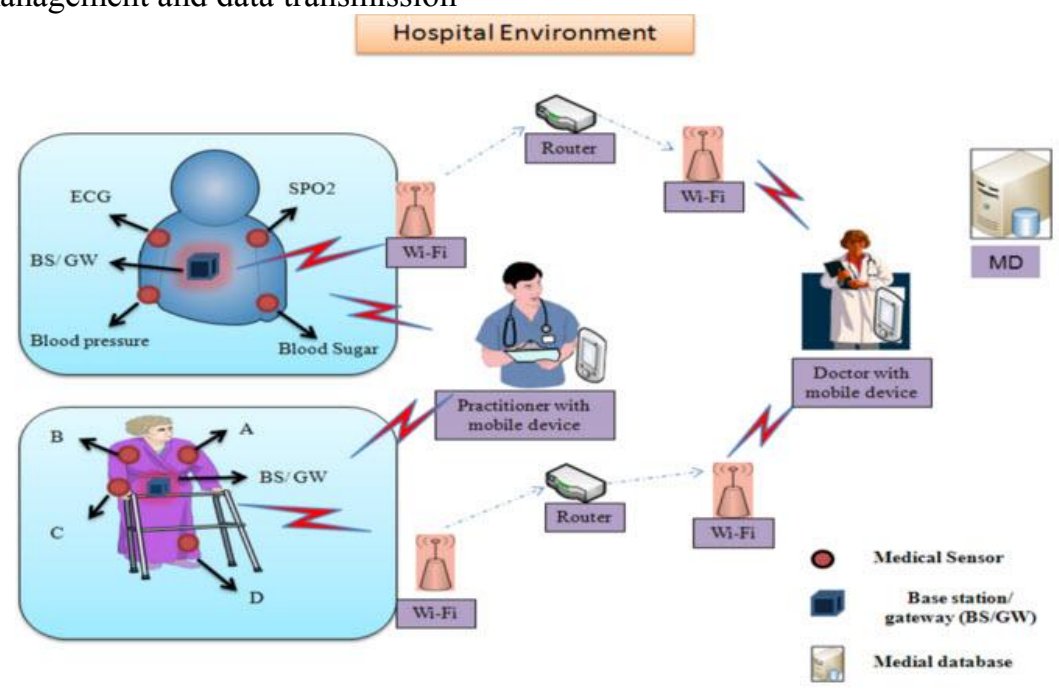

Figure 2: System of Wireless Health Monitoring 
Design of a automatic wireless health monitoring system is the main objective of this project. Monitor the display the body temperature of the patient is the significant function of this system [14].

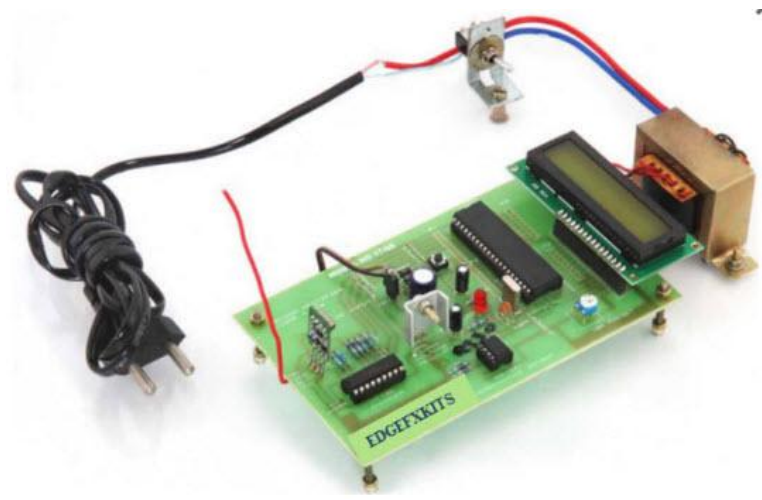

Figure 3: Project Kit of Automatic Wireless Health Monitoring System

\section{HEALTH MONITORING SYSTEM APPLICATIONS AND ADVANTAGES}

The system of automatic wireless health monitoring include following applications:

1. To transfer the data from the TX section to RX section wirelessly the wireless health monitoring system is utilized.

2. If it made certain changes in the project with the fastest mode of information about certain notices it also applicable for acknowledging the other user.

3. If a patient and doctors are at very far from each other and the whole detail about temperature and heartbeat is very necessary to give the doctors then this type of systems are required.

The system of automatic wireless health monitoring include following advantages:

1. When it compare with compact sensor it give a better

2. For multipurpose it can use in rural area.

3. device operation is very easy

4. Between the patients and the doctor and the patients associating the gap

\section{USing Wearable Devices the Portable HEALTH MONITORING SySTEMS}

There are several wearable portable devices are available that help to monitor the health. Some of them are as follows [15]:

1. Device of Wireless Smart Glucometer It evaluates the level of glucose in blood and then presents it on smartphone. The Wireless Smart Gluco-Monitoring System is a state-of-the-art this is approved by FDA and made by iHealth Lab Inc. performance

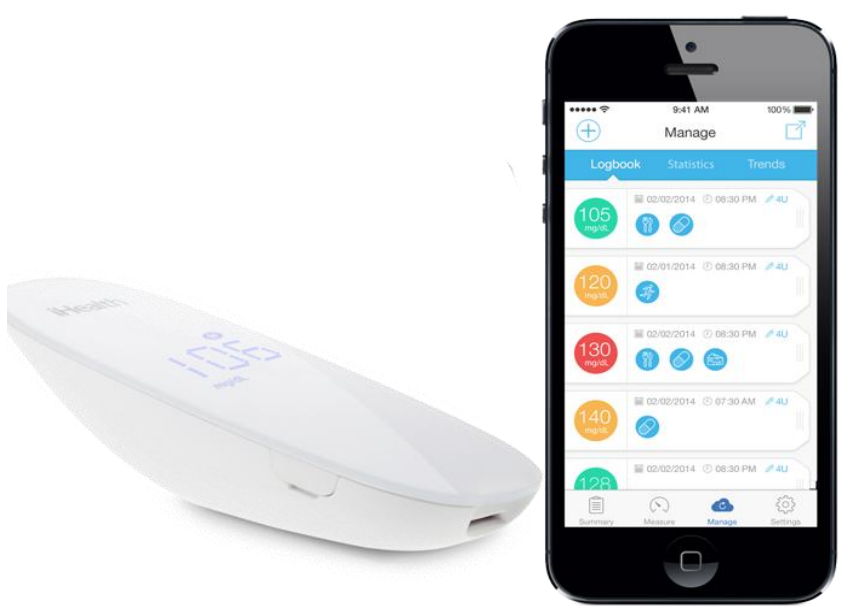

Figure 4: Wireless Smart Glucometer

2. Device of Remote Cardiac Monitoring System With cardiac arrhythmias to monitor their patients the BodyGuardian Heart allows healthcare practitioners and the data is send to the cloud platform of service.

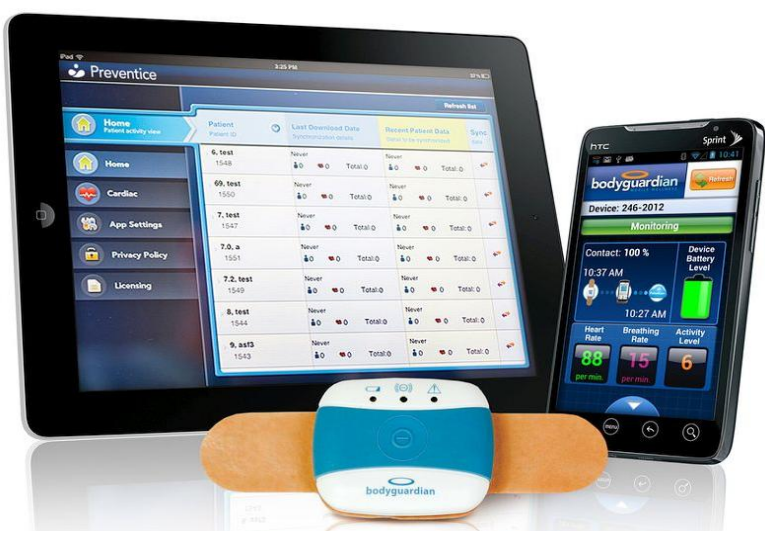

Figure 5: Remote Cardiac Monitoring System

3. Device of Pain Relief Device

Bid farewell to sciatica, joint inflammation, or Carpal Tunnel torment with TechCare Massager Touch 24 Modes, a mix of Transcutaneous Electrical Nerve Stimulator (TENS) and Powered Muscle Simulator (PMS) which conveys low-voltage heartbeats to the skin to animate nerve strands, obstructing the agony sign to mind.

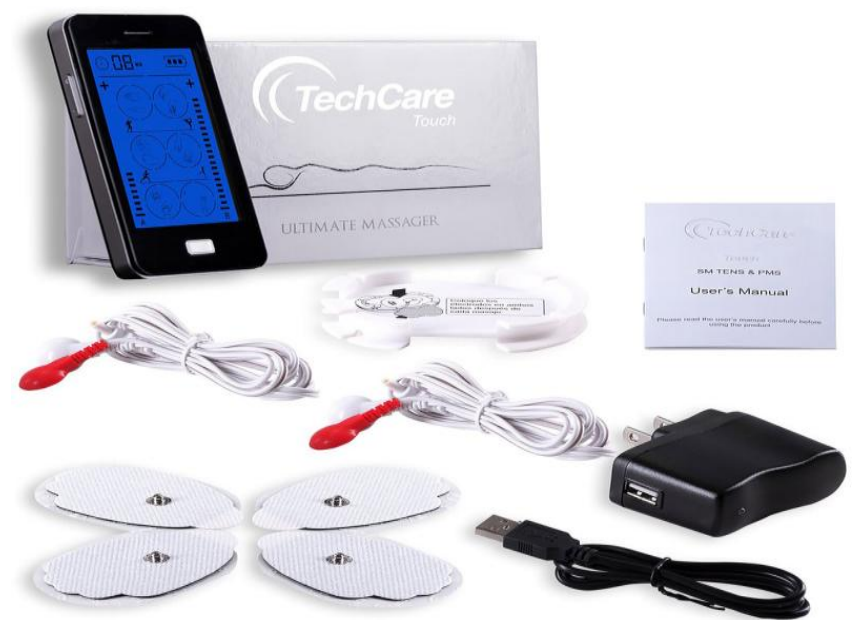

Figure 6: Pain Relief Device 


\section{Real-Time Alerting for Medical Science and Health Care}

\section{Device of Personal EKG}

For checking the health of heart anytime this device is used. it can used anywhere. It is a smart phone application. Kardia Mobile delivers a medical-grade electrocardiogram (ECG) to the smartphone very easily.
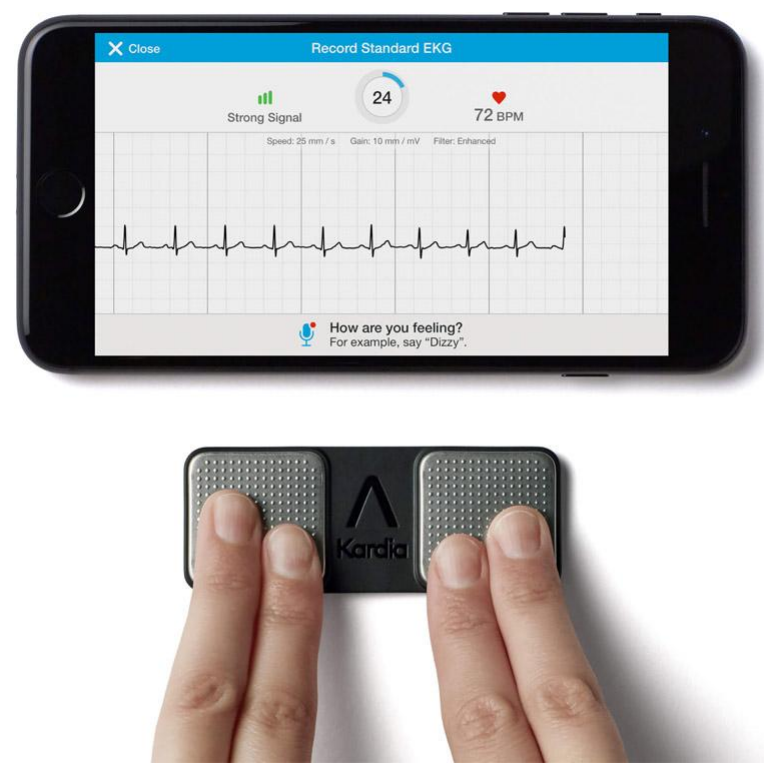

Figure 7: EKG monitor

5. Teeth Whitener

It is produced by G.L.O. (Guided Light Optic). It give along lasting result.

6. Device of Groundbreaking Smartphone Ultrasound Device

In remote areas to diagnose patients the first smartphone ultrasound imaging device was MobiUS SP1 that enables medical professionals.

7. Wireless Blood Pressure Monitor

Used for blood pressure monitoring. It is very easy to use and via Bluetooth it can synchronizes with smartphone automatically.

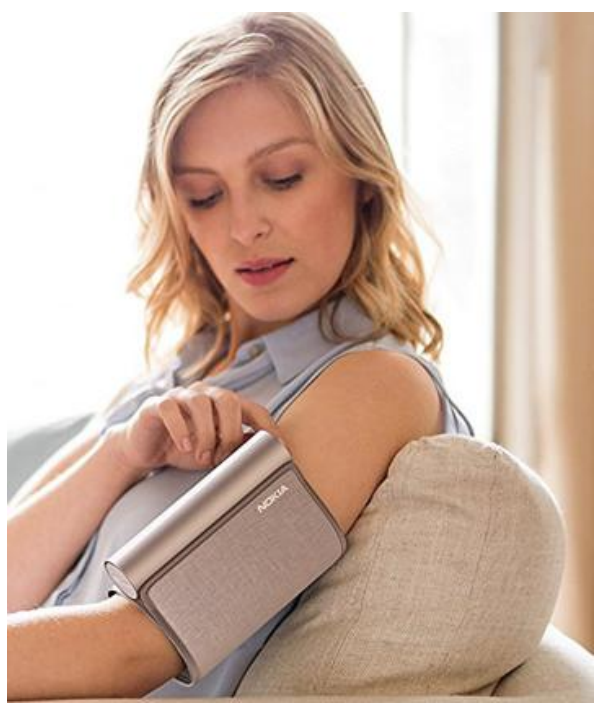

Figure 8: Wireless Blood Pressure Monitor

\section{Portable Gluten Tester}

It can be the lifesaver for people who have celiac disease or gluten allergies. It is designed by San Francisco-based startup 6 SensorLabs at the first time. It uses a proprietary app and one-time use test capsules and the data can track or share with other people. It is very easy to use.

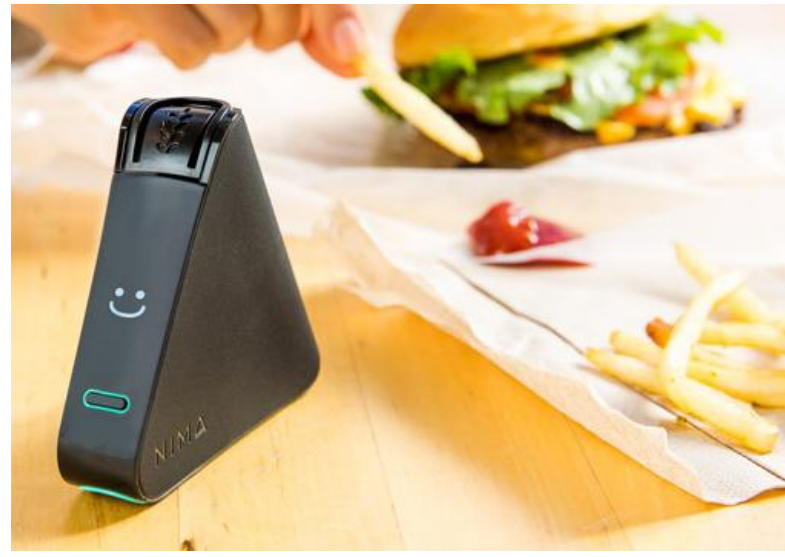

Figure 9: Portable Gluten Tester

\section{BioScarf}

For the previous air pollution masks the BioScarf can use as an alternative. It is more comfortable fashion accessory and warm. It lowers the respiratory health problems as it has an air filtration device.

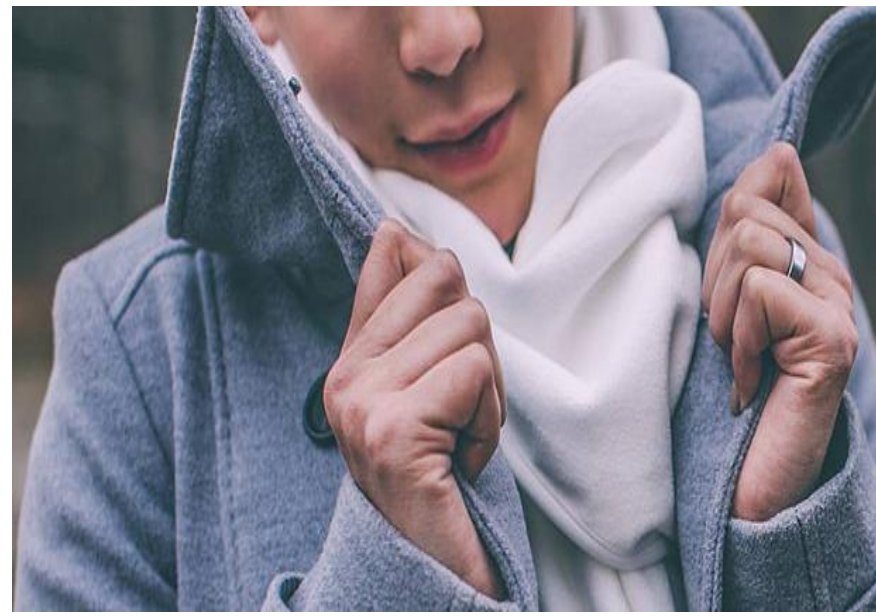

Figure 10: BioScarf

10. Device of Compact Air Pollution Monitor A device with the USB connectivity and size of $0.9 \times 0.9 \times 2.6$ inches the Compact Air Pollution device is very useful. It can use anywhere, anytime. It is best for allergies for asthma patients.

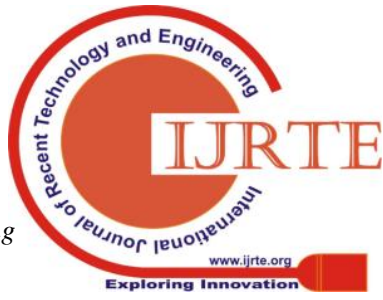




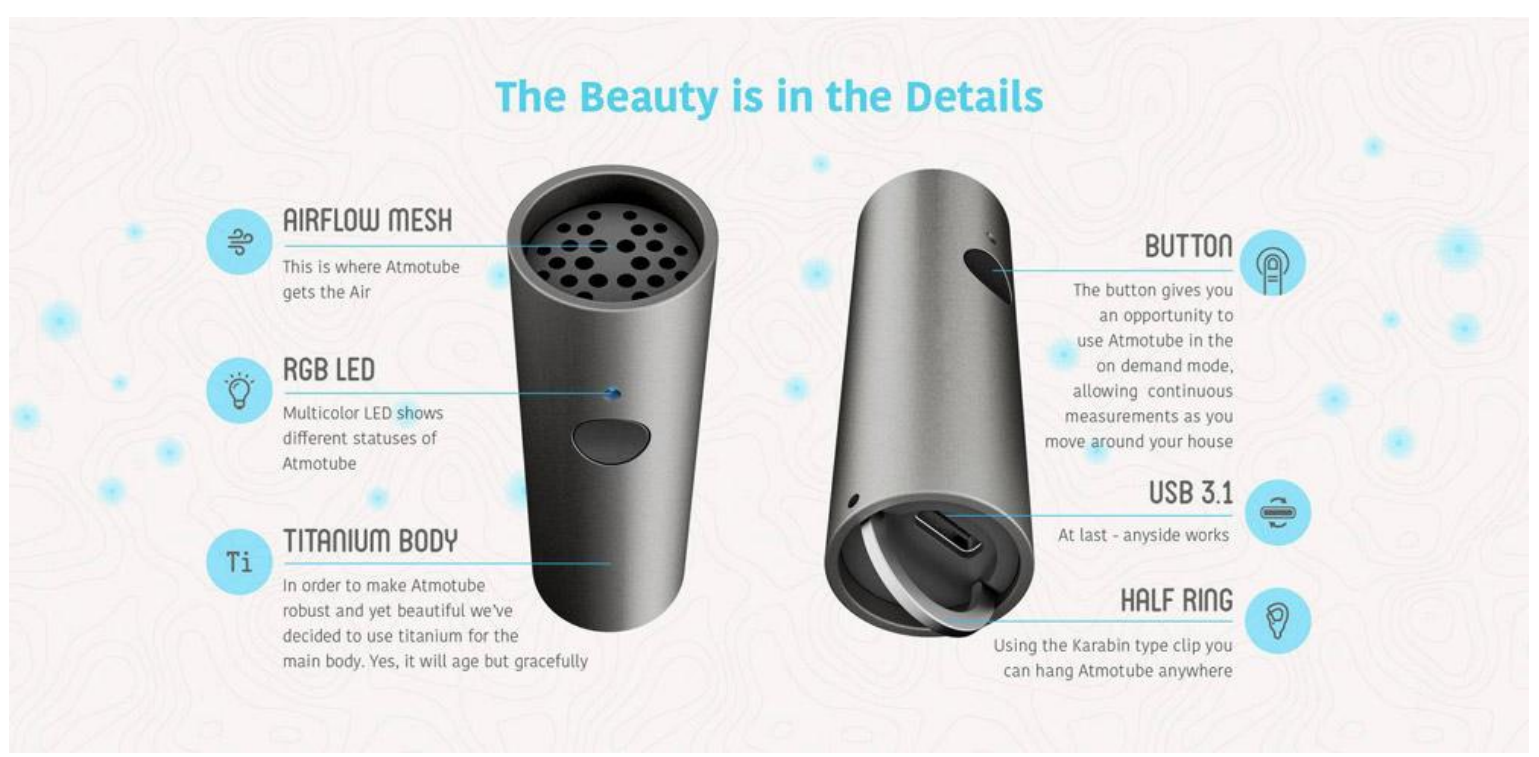

Figure 11: Compact Air Pollution Monitor

\section{Conclusion}

Without the need to manually request or refresh information the application of real time send and receive the data. These applications can be a device that instantly streams readings and monitors vitals to other devices or a data or it could be a general application which connects the patients to doctor. Without the need to revive or physically demand data the Real-time applications receive and send data instantaneously. It could be devices that screens vitals and immediately streams those readings to a database or different devices or for connecting the patient with doctors it could be a simple application of chat. The real-time communication power among specialists and patients is significant, however associations can possibly profit on the off chance that they are willing to embrace new arrangements. Luckily, incorporating real-time healthcare applications into existing correspondence frameworks is not as entangled as it may appear.

\section{REFERENCES}

1. C. Otto, Milenkovic, A., Sanders, C., Jovanov, E.,"System architecture of a wireless body area sensor network for ubiquitous health monitoring," Journal of Mobile Multimedia, vol. 1, pp. 07-326, 2004.

2. D.Malan, T.R.F.Fulford-Jones, M.Welsh,S.Moulton, CodeBlue: an ad-hoc sensor network infrastructure for emergency medical care, in: Proceedings of the Mobi-Sys 2004 Workshop on Applications of MobileEmbedded Systems (WAMES2004), Boston,MA, June,2004, pp.12-14.

3. D. Marinos, N. Vlisidis, C. Giovanis, F. Leonidas, C.Vassilopoulos, C. Aidinis, G. Pagiatakis, N. Schmitt, J. Klaue, T. Pistner, "Passenger health monitoring applications for aircraft cabin environment". International Conference for scientific computing to ocupatational engineering, IC-SCCE Athens june 2008.

4. Philippe Bonnet, Johannes Gaehrke and Praveen Sephardic, "Querying the Physical World", IEEE Personal Communications (2005), Vol. 9.

5. American Health Information Management Association Facsimile Transmission of Health Information (Updated) 2001.

6. Gerstle RS. E-mail communication between pediatricians and their patients. Pediatrics. 2004;114(1):317-21.

7. National Asthma Education and Prevention Program . Expert Panel Report 3: Guidelines for the Diagnosis and Management of Asthma. National Heart, Lung, and Blood Institute, National Institutes of Health; 2007.
8. Jenders RA, Corman R, Dasgupta B. Making the standard more standard: a data and query model for knowledge representation in the Arden syntax. AMIA Annu Symp Proc. 2003:323-30.

9. Zhu VJ, et al. An empiric modification to the probabilistic record linkage algorithm using frequency-based weight scaling. J Am Med Inform Assoc. 2009;16(5):738-45.

10. Erler, A. (2002). Introduction of Disease Management Programmes in Germany as Reflected by Differing Interests of Health Insurance Companies and the Federal Association of Statutory Health Insurance Physicians. Gesundheitswesen, 64(11), 572-577.

11. Geppert, A. \& Tombros, D. (1998). Event-based Distributed Workflow Execution with EVE. In Proceeding of the IFIP International Conference on Distributed Systems Platforms and Open Distributed Processing (Middleware'98) (pp. 427-442). The Lake District, Great Britain.

12. Iordache, S. D., Orso, D. \& Zelingher, J. (2001). A Comprehensive Computerized Critical Laboratory Results Alerting System for Ambulatory and Hospitalized Patients. Medinfo, 10(Pt 1), 469-473.

13. Shabot, M. M., LoBue, M. \& J, J. C. (2000). Wireless Clinical Alerts for Physiologic, Laboratory and Medication Data. In Proceedings of AMIA 2000 Annual Symposium (pp. 789-793). Los Angeles, USA.

14. Wagner, M. M., Pankaskie, M., Hogan, W., Tsui, F. C., Eisenstadt, S. A., Rodriguez, E. \& Vries, J. K. (1997). Clinical Event Monitoring at the University of Pittsburgh. In Proceedings of the American Medical Informatics Association (AMIA) 1997 Annual Symposium (pp. 188-192). Nashville, USA

15. Blobel, B. (2002). Comparing Concepts for Electronic Health Record Architectures. Studies in Health Technology Information, 90, 209-214. 